\section{p-ISSN 2476-9886 \\ e-ISSN 2477-0302 \\ T.Edu}

Voluı
Jurnal EDUCATIO

Jurnal Pendidikan Indonesia

Akses Online :

http://jurnal.iicet.org

Dipublikasikan oleh :

Indonesian Institute for Counseling, Education and Therapy (IICET)

Info Artikel:

Diterima: 08/10/2019

Direvisi: 08/13/2019

Dipublikasikan: 10/01/2019

\title{
Bentuk dan Fungsi Tale Haji dalam Acara Pelepasan Jamaah Haji di Desa Pondok Agung Kecamatan Pondok Tinggi Kota Sungai Penuh
}

\author{
Irwan Ficha Sanjaya ${ }^{1}$, Budiwirman ${ }^{2}$ \\ ${ }^{123}$ Universitas Negeri Padang
}

\begin{abstract}
The aim of this article is to express and explain about the form and function of Tale Haji while conducting the extrication event of Haji pilgrims based on Pondok agung village pondok tinggi subdistrict Sungai Penuh custom. The form of the Tale Haji displayed at this time is the area of study in this study. In the presentation and function of the Tale Haji which is an important performance in the release of the pilgrims is the focus of this research. This research was conducted with a qualitative research approach, with descriptive methods. Data collected by observation techniques, literature study, interviews, and documentation. The results showed that the Tale Haji performance was still maintained by the people of Pondok Agung Village to release the departing pilgrims. Tale Haji is displayed by standing making the shaf sideways, holding hands and facing each other between prospective worshipers with family and other communities. The Tale Haji function expresses the feelings of the prospective pilgrims who will go to Mecca and the feelings of families who leave through the Tale Haji poetry that contains messages and prayers.
\end{abstract}

Keywords: form, fuction, Tale Haji

This is an open access article distributed under the Creative Commons Attribution License, which permits unrestricted use,
distribution, and reproduction in any medium, provided the original work is properly cited. (C2019 by author.

\section{PENDAHULUAN}

Indonesia adalah Negara kepulauan yang terdiri dari gugusan pulau besar dan kecil, yang membentang dari Sabang sampai Marauke. Pulau-pulau tersebut dihuni oleh berbagai suku dengan latar belakang budaya yang berbeda. Perbedaan suku juga menghasilkan corak budaya yang berbeda pula. Soekanto (1990:187), menyatakan bahwa masyarakat adalah orang yang hidup bersama yang menghasikan kebudayaan. Hal ini mengandung pengertian bahwa tak ada masyarakat yang tidak mempunyai kebudayaan dan sebaliknya tak ada kebudayaan tanpa masyarakat sebagai wadah pendukungnya.

Kebudayaan adalah sebagai keseluruhan pengetahuan, kepercayaan dan nilai yang dimiliki oleh manusia sebagai makhluk sosial. Budaya itu sendiri beragam bentuknya, diantaranya adalah adat istiadat, upacara adat, norma-norma sosial, sosial budaya, dan kesenian tradisional yang lahir dan berkembang ditengah-tengah masyarakat. Keragaman budaya tersebut menjadi ciri kebudayaan dari daerah dari mana budaya itu berasal. Harjono (1986:92) menyebutkan bahwa Kroeber dan Kluckhohn pernah mengumpulkan 160 defanisi tersebut. 
Masyarakat Sungai Penuh yang memiliki keragaman kebudayaan dan kesenian tradisi. Salah satunya adalah kesenian Tale. Tale yang artinya nyanyian rakyat, berasal dari kata Tala (sanskerta) berarti ukuran bunyi.Iskandar Zakaria (1984:58) menyatakan mengenai Tale bahwa: Ada dua pendapat mengenai asal kata Tale ini. Pertama berasal dari kata Arab, yaitu Tahlil, yaitu pernyataan umat Islam bahwa tidak ada tuhan selain Allah, dengan bacaan Lailahaillallah. Bacaan ini terus menerus dikomandokan oleh seorang imam. Bacaan tersebut dilaksanakan ketika adanya acara-acara keagamaan. Misalnya selesai shalat, ada acara sunah rasul, khatam Qur'an dan sebagainya. Dari perkataan itu akhirnya menjadi Tale yang berarti lagu, karena orang bertahlil seperti bernyanyi pula, berirama. Pendapat kedua berasal dari kata tali, dalam bahasa kerinci disebut Talai.

Masyarakat Sungai Penuh di Desa Pondok Agung Kecamatan Pondok Tinggi menganggap Ibadah Haji pada zaman dahulu merupakan sebuah peristiwa yang sangat luar biasa. Orang Sungai Penuh pada masa itu beranggapan bahwa orang-rang yang akan menunaikan ibadah haji dianggap tidak akan kembali lagi karena saat itu waktu tempuh yang lama sampai berbulan-bulan dan perjalanan yang tempuh sangat berat sekali karena menggunakan kapal. Maka dari itu masyarakat Sungai Penuh pada saat itu menjadikan Tale Haji sebagai media untuk mengungkapkan perasaan sedih, haru dan emosional karena melepas keberangkatan calon jamaah haji agar calon jamaah haji bisa ingat untuk selalu menjaga diri dengan baik, selamat pergi dan selamat pulang, mendapatkan haji yang yang diterima oleh Allah.SWT dan tidak melupakan keluarga yang ditinggalkan di kampong halaman.

Sampai saat ini di tengah kemajuan zaman dan transportasi masyarakat Desa Pondok Agung Kecamatan Pondok Tinggi Kota Sungai Penuh masih menampilkan Tale Haji untuk mengiringi keberangkatan anggota keluarga mereka yang akan menunaikan ibadah haji. Kegiatan Tale Haji saat ini dilaksanakan ditiap rumah yang anggota keluarganya akan berangkat haji ke Mekah. Acara pelepasan jamaah haji juga perlu minta izin kepada Depati dan Ninik Mamak yang ada di derah tersebut. Artikel ini menginformasikan tentang bentuk dan fungsi Tale Haji yang ditampilkan saat dulu dan saat sekarang ini dalam acara pelepasan jamaah haji di Desa Pondok Agung Kecamatan Pondok Tinggi Kota Sungai Penuh.

\section{METODE}

Penelitian ini akan dilakukan di Desa Pondok Agung Kecamatan Pondok Tinggi Kota Sungai Penuh. Penelitian ini menggunakan pendekatan kualitatif, yang bersifat deskriptif analisis. Adapun pengumpulan data dilakukan melalui observasi terhadap bentuk pelaksanaan pertunjukan Tale Hajidan bagaimanafungsi pertunjukan Tale Haji dalam acara pelepasan jamaah haji secara adat.

Wawancara dilakukan untuk mengumpulkan informasi dari masyarakat mengenai pertunjukan Tale Haji. Selain itu, wawancara juga dilakukan untuk mengumpulkan tanggapan masyarakat terhadap fungsi pertunjukan Tale Haji. Dokumentasi data dari arsip, laporan kegiatan, hasil penelitian dikumpulkan oleh peneliti sebagai data penelitian. Peneliti, sebagai instrumen kunci, merencanakan penelitian dengan membuat grid penelitian dan melakukan pengumpulan data dengan bantuan media audio visual.

Analisis dilakukan melalui tahapan pengumpulan data melalui wawancara, observasi dan dokumentasi pengumpulan data pertunjukan Tale Haji, konsep, sertaisi yang di gunakan darihasil proses kebudayaan. Semua data dipilih untuk dianalisis dengan mengevaluasi permasalahan dan dibimbing oleh pertanyaan penelitian dan teori pendukung. Peneliti kemudian memverifikasi data yang valid dan menafsirkannya. Validasi data dilakukan melalui diskusi antar rekan kerja dan triangulasi. Validasi data dilakukan dengan menempatkan data dalam situasi yang berbeda dan diulang untuk menyesuaikan diri dengan pertanyaan yang diajukan.

\section{HASIL}

\section{Perkembangan Tale Haji di Desa Pondok Agung}

Tale Haji berkembang di Daerah Desa Pondok Agung Kecamatan Pondok Tinggi Kota Sungai Penuh yaitu setelah masuknya agama islam di daerah ini. Tidak di ketahui secara Pasti dari mana dan siapa pencipta kesenian Tale ini bermula. Pada zaman dahulu, masyarakat di daerah ini menunaikan ibadah haji menggunakan kendaraan yang sederhana, yaitu menggunakan kuda untuk pergi ke pelabuhan dan menggunakan kapal laut menuju ke mekkah. Karena jarak daerah sungai penuh dengan mekkah sangatlah jauh, sehingga perjalanan yang di tempuh memakan waktu kurang lebih tiga bulan. Selain itu, jalan darat dari daerah Sungai Penuh hingga 
penyeberangan, harus menempuh jalan yang sangat sulit, dikarenakan daerah tersebut dikelilingi hutan dan perbukitan.

Sampai saat sekarang ini di tengah kemajuan zaman dan transportasi memudahkan keberangkatan calon jamaah haji untuk pergi ke mekkah dengan waktu yang lebih singkat dari pada dahulu. Masyarakat di Desa Pondok Agung masih tetap menampilkan Tale Haji dalam acara pelepasan jamaah haji dan tidak bisa meninggalkan kesenian Tale Haji walaupun zaman terus berkembang. Kesenian Tale Hajipun saat ini sudah menjadi pertunjukan hiburan tersendiri bagi calon jamaah haji yang menampilkan kesenian tersebut.

\section{Bentuk Penyajian Tale Haji dalam Acara Pelepasan Jamaah Haji}

Penampilan tale baru boleh dimulai setelah upacara adat depati dan ninik mamak di rumah calon jamaah haji, pada saat penyampaian perno ninik mamak untuk memberi izin untuk melaksanakan penampilan Tale Haji. Tale Haji di Desa Pondok Agung dahulu dilaksanakan pada siang hari sesudah sholat dzuhur, sore sesudah sholat ashar, dan malam sesudah sholat isha yang dilakukan sampai tengah malam, hingga bisa sampai subuh. Namun sekarang sudah dibatasi dan biasanya pada saat sekarang ini dilaksanakan pada siang hari sesudah sholat dzuhur sampai sore hari.

Tale Haji dilakukan dengan cara berdiri membuat shaf kesamping, saling berpegangan tangan dan saling berhadap-hadapan antara calon jamaah dengan ninik mamak dan masyarakat yang hadir dengan gerakan kaki maju dan mudur. Jika jumlah orang-orang yang mengikuti Tale Haji banyak maka shaf akan ditambah di belakangnya. Syair Tale Haji yang di nyanyikan berisikan pesan-pesan dan doa-doa untuk keselamatan orang yang akan berangkat haji.

Penonton yang hadir menjadi unsur pendukung penampilan Tale Haji. Dalam Tale Haji keberadaan penonton menjadi penyemangat penampilan Tale Haji. Petale bahkan sering mengikut sertakan orang-orang yang menonton untuk terlibat dalam penampilan mereka. Keterlibatan penonton dalam penampilan Tale Haji dapat di lihat dari pengucapan ulang atas konteks Tale yang disampaikan oleh Petale, misalnya ketika Petale menyebutkan ulang beberapa baris kalimat Talenya, maka penonton yang terpengaruh oleh konteks tersebut akan mengulang untuk menyebutkannya.

\section{Fungsi Pertunjukan Tale Haji dalam Acara Pelepasan Jamaah Haji}

Fungsi merupakan suatu yang menjembatani kemanfaatan dari suatu kegiatan yang digunakan oleh manusia untuk mencapai tujuan, baik itu tujuan praktis yang bersifat konkrit jasmani maupun fungsi dan tujuan untuk mecapai suatu kepuasan, nilai-nilai yang bersifat rohani. Fungsi mempunyai kaitan erat dengan persoalanpersoalan yang di ekspresikan manusia sebagai bentuk komunikasi, dalam kehidupan sosial dan bermanfaat bagi masyarakat. Sebagai kesenian pertunjukan dalam acara pelepasan jamaah haji, Tale Haji mempunyai fungsi sebagai kesenian tradisi yang harus dipahami oleh masyarakat, bukan saja sebagai alat komunikasi dengan masyarakat, tetapi sesuatu yang menjadi bagian dari sistem kehidupan sosial budaya masyarakat dan sebagai identitas bagi daerahnya.

Pertunjukan Tale Haji dipertunjukan pada siang hari setelah semua kegiatan acara dalam acara pelepasan jamaah haji yang ada sudah dilakukan. Tale Haji yang ditampilkan diakhir acara menjadi media untuk calon jamaah haji dan keluarga serta masyarakat sekitar agar bisa menuangkan segala macam perasan mereka kedalam syair Tale Haji yang berisi pesan-pesan ataupun doa-doa agar selalu berhati-hati selama perjalanan dan selalu mengingat keluarga dan orang-orang dikampung halaman.

\section{PEMBAHASAN}

Sebagai salah satu kesenian tradisi, kesenian Tale merupakan bagian dari kebudayaan masyarakat Desa Pondok Agung yang masih tetap ditampilkan oleh masyarakatnya. R. Linton (Usman Pelli, 1994:23) mengemukakan bahwa kebudayaan adalah konfigurasi dari tingkah laku yang unsur-unsur pembentukannya didukung dan diteruskan oleh anggota dari suatu masyarakat.

Kemudian Mursal Esten (1993:11) menjelaskan tradisi adalah kebiasaan turun menurun sekelompok masyarakat berdasarkan nilai-nilai budaya masyarakat yang bersangkutan. Tradisi memperlihatkan bagaimana anggota masyarakat bertingkah laku, baik dalam kehidupan yang bersifat gaib atau keagamaan. Edy Sedyawati (1981:119) menjelaskan kesenian di selenggarakan demi kelangsungan suatu tradisi dan kesenian merupakan alat penguat penguat tradisi. Kesenian tradisi terikat oleh suatu sistem tata nilai yang di anut, dipelihara, dan dipertahankan dalam kehidupan bersama dalam rentan waktu yang lama. 
Murgiyanto (1986: 14) menjelaskan bentuk kesenian dapat dibagi menjadi dua yaitu isi dan bentuk luarnya. Isi berhubungan dengan tema atau cerita dalam pertunjukan itu sendiri. Bentuk dalam kesenian adalah sebagai wadah untuk menuangkan isi yang disampaikan oleh seorang seniman (Prihatini, 2008:95).

Jika dikaitkan dengan pertunjukan kesenian Tale Haji, maka kesenian Tale Haji termasuk dalam kesenian tradisi Karena sudah dilakukan sejak dulu hingga sekarang. Dari bentuk dan isi, kesenian Tale Haji menjadi sebuah kesenian yang memiliki cerita dan pesan-pesan didalamnya. Kesenian tradisi juga tidak lepas dari sebuah kebudayaan dan kebudayaan pembentukannya didukung dan diteruskan oleh anggota dari suatu masyarakat. Kata tradisi sendiri tak lepas dari sebuah kebiasaan suatu masyarakat secara turun-temurun dari satu generasi ke generasi berikutnya baik itu dalam bentuk tingkah laku ataupun kesenian yang ada dalam suatu masyarakat itu sendiri. R. Bascom (1965) menyebutkan bahwa folklore (dalam hal ini sastra lisan) memiliki beberapa fungsi, yakni sebagai hiburan, sebagai alat pengesahan pranata-pranata dan lembaga kebudayaan, sebagai alat pendidikan anak-anak, dan sebagai pemaksa dan pengawas agar norma-norma masyarakat selalu dipenuhi.

Sementara itu menurut Sedyawati (2007: 293), berbagai fungsi seni pertunjukan yang dapat dikenali, baik lewat data masa lalu maupun data etnografi masa kini, meliputi fungsi-fungsi religius, peneguhan integrasi sosial, edukatif, dan hiburan, yang berubah dari zaman ke zaman adalah penekanan pada fungsi-fungsi maupun bentuk-bentuk pernyataannya.

Berdasarkan fungsi-fungsi di atas, maka tale haji sebagai sebuah tradisi lisan masyarakat Sungai Penuh khususnya masyarakat Pondok Agung memiliki beberapa fungsi. Fungsi pertunjukan Tale Haji dalam acara pelepasan jamaah haji ini adalah untuk melepas orang yang akan berangkat haji dengan syair Tale sebagai ungkapan perasaan akan pergi jauh dari keluar, pesan-pesan untuk selalu berhati-hati selama perjalanan dan do'a agar selamat pergi dan selamat pulang. Sebagai kesenian tradisi dalam acara pelepasan jamaah haji secara adat, Tale Haji mempunyai fungsi yang menjadi bagian dari kehidupan dalam keagamaan masyarakat, sebagai identitas bagi daerahnya dan sebagai bagian dari pelestarian kesenian tradisi masyarakat di Desa Pondok Agung Kecamatan Pondok Tinggi Kota Sungai Penuh.

\section{KESIMPULAN}

Berdasarkan uraian dari bab-bab sebelumnya, maka akhir dari penelitian ini dapat diambil beberapa kesimpulan. 1) Bentuk pertunjukan Tale Haji dalam acara pelepasan jamaah haji di Desa Pondok Agung Kecamatan Pondok Tinggi Kota Sungai Penuh: Tale Haji merupakan salah satu jenis kesenian tradisi yang terdapat di daerah Sungai Penuh pada umumnya dan pada masyarakat Pondok Tinggi khususnya. Mengenai pertunjukan Tale Haji dalam acara pelepasan jamaah haji ini tak lepas dari keberadaan kesenian Tale Haji itu sendiri di Desa Pondok Agung yang dinilai sangat penting mengingat sudah Banyak hilangnya kesenian Tale yang lain selain Tale Haji yang masih bertahan; 2) Fungsi pertunjukan Tale Haji dalam acara pelepasan jamaah haji di Desa Pondok Tinggi Kecamatan Pondok Tinggi Kota Sungai Penuh. Fungsi pertunjukan Tale Haji dalam acara pelepasan jamaah haji ini adalah untuk melepas orang yang akan berangkat haji dengan syair Tale sebagai ungkapan perasaan akan pergi jauh dari keluar, pesan-pesan untuk selalu berhati-hati selama perjalanan dan do'a agar selamat pergi dan selamat pulang. Sebagai kesenian tradisi dalam acara pelepasan jamaah haji secara adat, Tale Haji mempunyai fungsi yang menjadi bagian dari kehidupan dalam keagamaan masyarakat, sebagai identitas bagi daerahnya dan sebagai bagian dari pelestarian kesenian tradisi masyarakat di Desa Pondok Agung Kecamatan Pondok Tinggi Kota Sungai Penuh.

\section{REFERENSI}

Bascom, W.R. 1965. "Four Functions of Folklore," dalam Dundes, A. (ed.). The Study of Folklore. Englewood Cliffs, N.J.:Printice-Hall Inc.

Sedyawati, Edi. 2007. Budaya Indonesia: Kajian Arkeologi, Seni dan Sejarah. Jakarta: PT. Raja Grafindo.

Esten, Mursal. 1993. Struktur Sastra Lisan. Jakarta: Yayasan Obor

Harjono. 1986.Pengantar antropologi. Bandung: Bina Cipta.

Iskandar, Zakaria. 1984. Tambo Sakti Alam Kerinci. Jakarta: Departemen Pendidikan dan Kebudayaan Proyek Penerbitan Buku Satra dan Daerah.

Murgiyanto. 1986. Kesenian dan Kebudayaan. Surakarta: STSI Press

Pelly, Usman. 1994. Teori-teori Sosial Budaya. Jakarta: Proyek Pembinaan dan Peningkatan Mutu Tenaga Kerja Kependidikan Direktoral Jendral Pendidikan Tinggi. Debdikbud.

Prihatini, Sri Nanik. 2008. Seni Pertunjukan Rakyat Kedua. Surakarata:Pascasarjana dan ISI Press Surakarta. 
Sedyawati, Edi. 2007. Budaya Indonesia: Kajian Arkeologi, Seni dan Sejarah. Jakarta: PT. Raja Grafindo.

Soekanto,soerjono.1990. sosiologi suatu pengantar. Jakarta: pt rajagrafindo persada 